\title{
Alternative splicing of dystrophin mRNA complicates carrier determination: report of a DMD family
}

\author{
U Lenk, S Demuth, U Kräft, R Hanke, A Speer
}

\begin{abstract}
Carrier determination is important for genetic counselling in DMD/BMD families. The detection of altered PCR amplified dystrophin mRNA fragments owing to deletions, insertions, or point mutations has increased the possibilities of carrier determination. However, problems may occur because of alternative splicing events. Here we present a family with a DMD patient characterised by a deletion of exons 45 to 54 . At the mRNA level we detected a corresponding altered fragment which served for carrier determination. The mother and the sister of the patient showed the same altered dystrophin mRNA fragment as the patient and are therefore carriers. In the mother two additional altered dystrophin mRNA fragments were detectable, obviously resulting from alternative splicing in the normal allele. The grandmother and two other related females of the patient possess only the normal mRNA fragment. In a further female we detected an altered fragment owing to an mRNA deletion of exon 44. This fragment is created either by alternative splicing or a new mutation. Therefore, the carrier status of this female is still ambiguous indicating problems in carrier determination by the method of dystrophin mRNA analysis. ( $\mathcal{H}$ Med Genet 1993;30:206-9)
\end{abstract}

Carrier determination is important for genetic counselling of families with Duchenne or Becker muscular dystrophy (DMD/BMD) and includes biochemical, physical, and molecular analyses. DNA based methods involve linkage analysis and mutation detecting techniques like gene dosage estimation or junction fragment detection. ${ }^{1-6}$ The introduction of DNA analysis has resulted in substantial progress in carrier determination, but misdiagnoses owing to crossover events and misinterpretations of gene dosage data cannot be neglected. For deletions, the detection of a junction fragment is a rare event requiring the technically difficult pulsed field gel electrophoresis. The analysis of dystrophin mRNA transcripts from peripheral blood lymphocytes $^{78}$ has increased the possibilities for carrier determination.

Using a system consisting of reverse transcriptase and 10 sets of overlapping nested PCR reactions it is possible to amplify every region of the $11 \mathrm{~kb}$ dystrophin coding sequence. ${ }^{910}$
Reactions bridging deletions or duplications result in altered PCR products. ${ }^{11-14}$ Here we report a DMD family in which carrier determination using this method was complicated by the presence of alternative splicing events.

Material and methods

REVERSE TRANSCRIPTION AND NESTED PCR Total RNA was prepared from peripheral blood lymphocytes ${ }^{15}$ and about $500 \mathrm{ng}$ of total lymphocyte RNA were transcribed using the primers DMD N7b and DMD 8b. Nested PCR was performed as described by Roberts $e t$ $a l^{10}: 10 \mu \mathrm{l}$ of the PCR assay was electrophoresed in a $2 \%$ agarose gel.

PRIMER SEQUENCES

Set 7

DMD N7a TCATAGCAAGAAGACAGCAGC DMD N7b CTCGTTGATATCCTCAAGGTC DMD N7c GTGGAAAGGGTGAAGCTACAG DMD N7d ACTTGATCAAGCAGAGAAAGC Set $8(10)$

DMD 8a CTAGAAATGCCATCTTCCTTG

DMD 8b CTCAGGAGGCAGCTCTCTGG

DMD 8c CTGCTCTGGCAGATTTCAAC

DMD 8d GGGCTCCTGGTAGAGTTTCTC

DIRECT SEQUENCING OF PCR PRODUCTS

Nested PCR products were purified from $2 \%$ agarose gels using USBioclean MP (USB) and sequenced with fmol DNA Sequencing System (Promega) using ${ }^{32} \mathrm{P} \gamma \mathrm{ATP}$ labelled primer DMD N7c.

\section{Results}

Fig 1 shows the pedigree of the DMD family requesting genetic counselling. A deletion of exon 45 to 54 inclusive was identified in patient III. 5 by Southern transfer/hybridisation and PCR. A junction fragment to be used for carrier determination was not detectable. Therefore we used primer sets 7 and 8 covering exons 43 to 51 and 51 to 58 respectively for dystrophin mRNA analysis.

PCR products resulting from set 7 amplifications are summarised in fig 2 . For the DMD patient III.5, who is deleted for exon 51 , the target sequence of primers N7b,d, no PCR product is visible. The females $\mathrm{I} \cdot 2, \mathrm{II} \cdot 2, \mathrm{II} \cdot 4$, III $\cdot 2$, III $\cdot 6$, and III $\cdot 8$ show a normal full sized fragment of $1271 \mathrm{bp}$. In the mother (II.2) of the patient two additional fragments of $797 \mathrm{bp}$ and $611 \mathrm{bp}$ occur. By sequencing we identified 
1

II

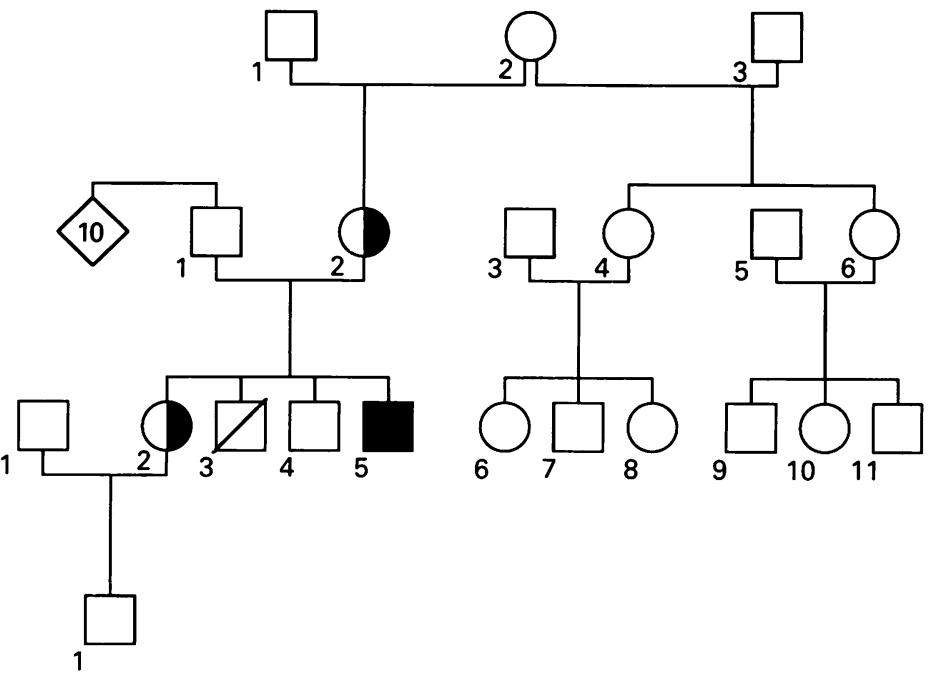

Figure 1 Pedigree of the DMD family requesting genetic counselling. Genomic DNA of patient III.5 was analysed by Southern transfer/hybridisation with cDNA probes cf $56 a, b$ and by PCR covering exons 41 to 55. A DNA deletion of exons 45 to 54 was detectable. Family members $I \cdot 2, I I \cdot 2, I I \cdot 4, I I I \cdot 2, I I I \cdot 5, I I I \cdot 6$, and $I I I \cdot 8$ were analysed by nested amplification of reverse transcribed $m R N A(R T-P C R)$.

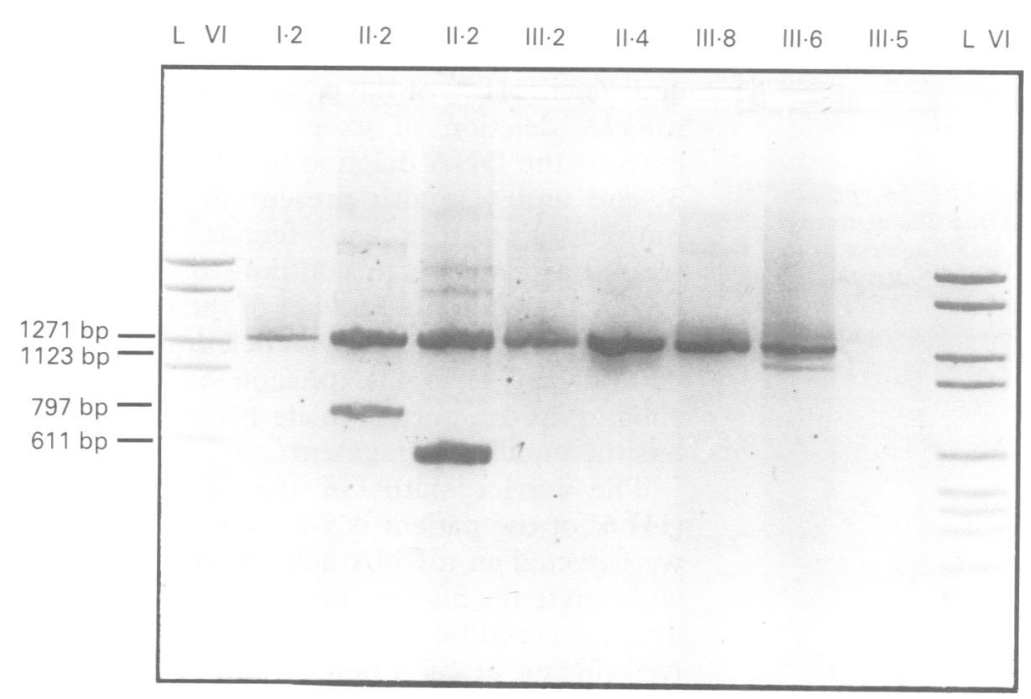

Figure 2 Products of nested RT-PCR spanning exons 43 to 51 (set 7, see also diagram in fig 7) shown in an ethidium bromide stained $2 \%$ agarose gel. For the DMD patient III. 5 a signal is missing owing to the deletion of exons 45 to 54 . The mother (II.2) has two altered fragments of $797 \mathrm{bp}$ and $611 \mathrm{bp}$ in addition to the full sized $1271 \mathrm{bp}$ product. Female III.6 shows a faint additional band of $1123 \mathrm{bp}$.

an mRNA deletion of exons 45 to 47 for the $797 \mathrm{bp}$ fragment (fig 3) and an mRNA deletion of exons 45 to 48 for the $611 \mathrm{bp}$ fragment. The female III 6 also shows an altered fragment of $1123 \mathrm{bp}$. The sequencing data show an mRNA deletion of exon 44 (fig 4).

By use of primers $8 b, d$ and $7 a, b$, which bridge the DNA deletion, a normal full sized PCR product of $2460 \mathrm{bp}$ is expected (fig 5). All females show a normal full sized fragment. In addition, the mother (II 2 ) and sister (III-2) of the patient have a smaller fragment of $681 \mathrm{bp}$. The same fragment is also detectable in the DMD patient. By sequencing we observed an mRNA deletion of exons 45 to 55 (fig 6), which includes one more exon than in the DNA deletion. In addition to this fragment the patient has two other PCR products of $871 \mathrm{bp}$ and $723 \mathrm{bp}$. Sequencing data indicate that they

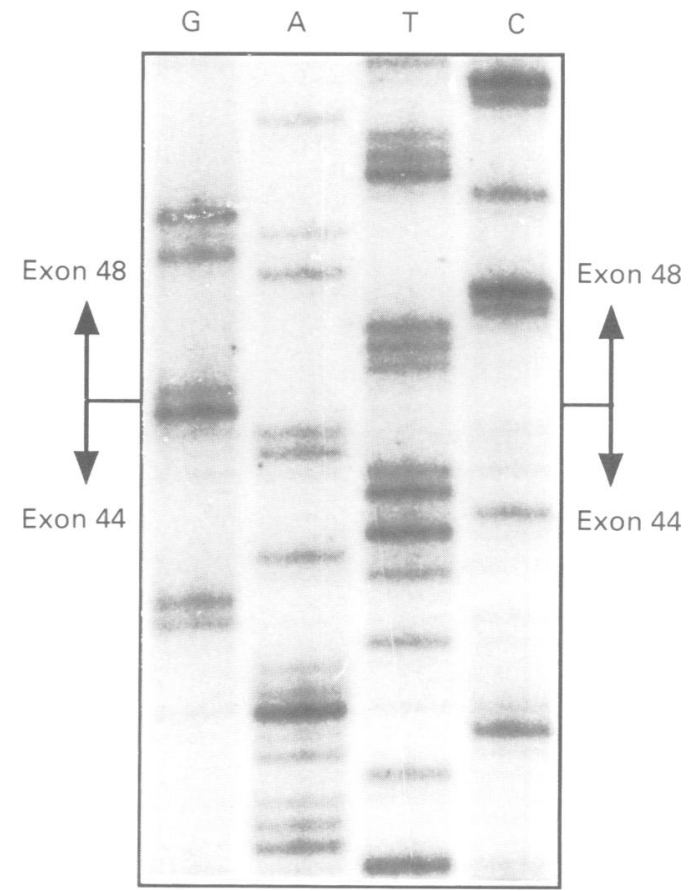

Figure 3 Direct sequence analysis of the $611 \mathrm{bp}$

fragment of female II. 2 amplified with primer set 7 . The sequence data indicate splicing of exon 44 into exon 48. Therefore exons 45 to 47 are missing from the $m R N A$ transcript.

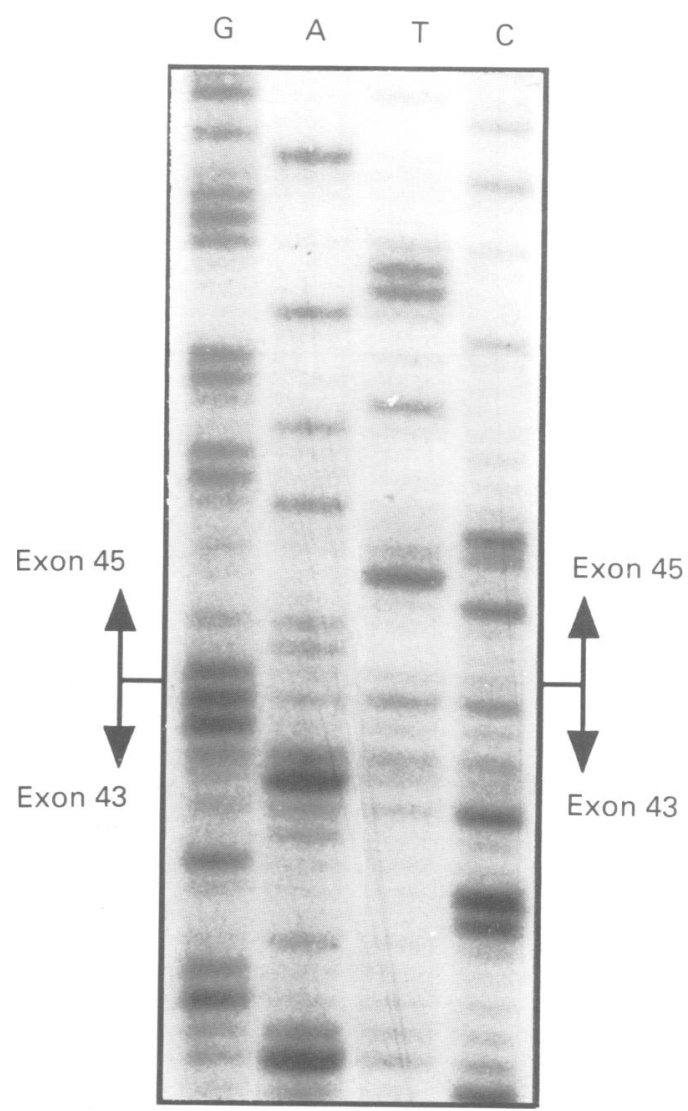

Figure 4 Direct sequence analysis of the $1123 \mathrm{bp}$ band of female III. 6 amplified with primer set 7 . Splicing of exon 43 into exon 45 indicates that exon 44 is missing from the $m R N A$ transcript. 


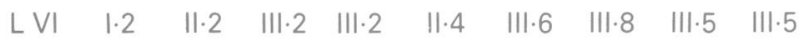

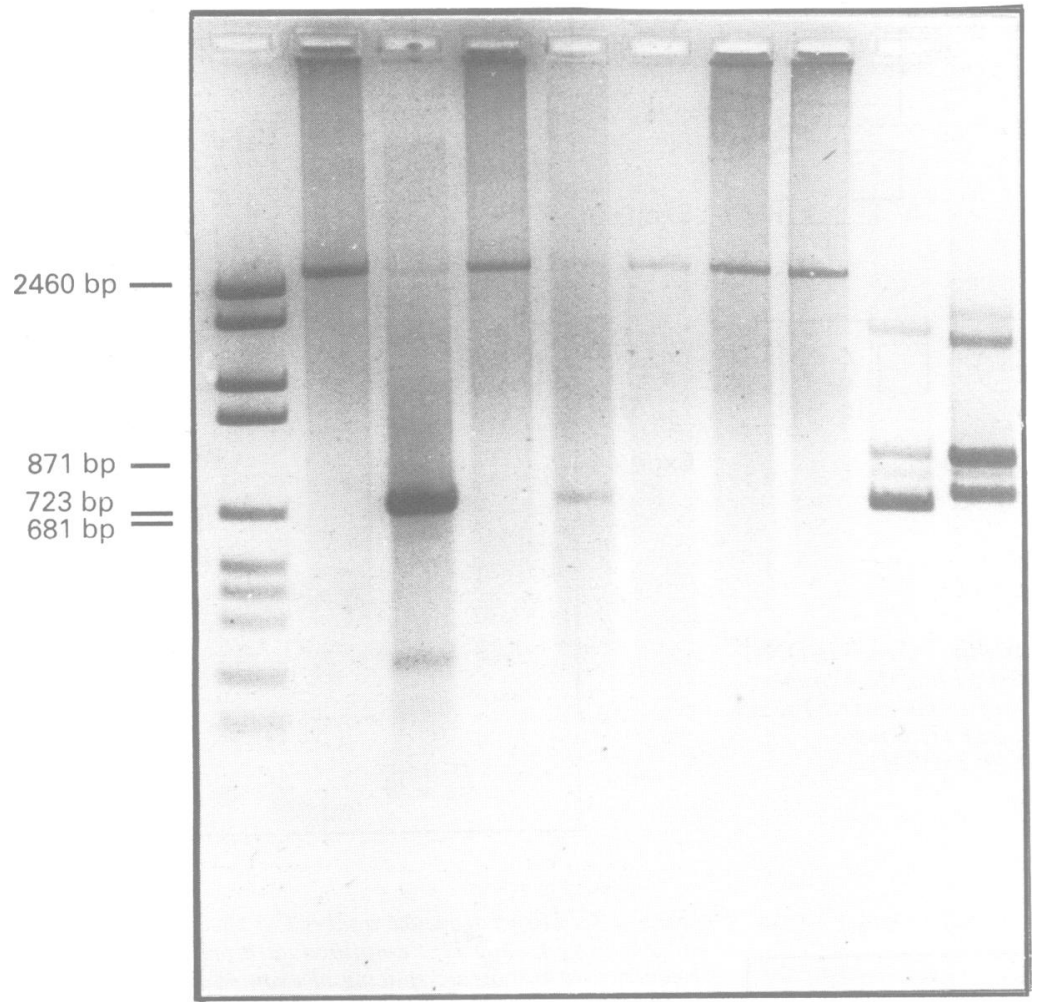

Figure 5 Summarised results of nested $R T-P C R$ crossing exons 43 to 58 (primer combinations: N7a-8b;N7b-8). Products were electrophoresed in a $2 \%$ agarose gel. The mother II.2 and sister III.2 have the same 681 bp reduced size fragment as the DMD patient III.5. Therefore they were identified as carriers. All females tested show the normal fragment of $2460 \mathrm{bp}$. Patient III.5 has additional products of $871 \mathrm{bp}$ and 723 bp representing alternative spliced transcripts. Some higher bands were identified as heteroduplex molecules.

$11 \cdot 2$
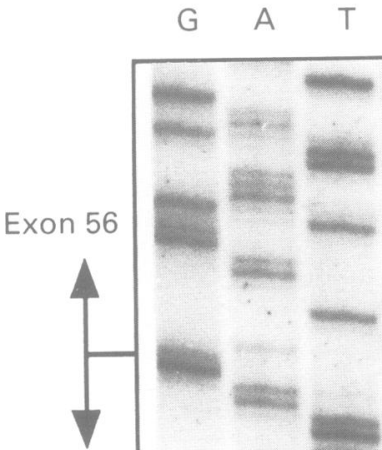

Exon 44

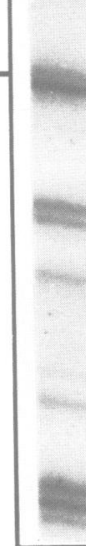

Figure 6 Direct sequence analysis of the $681 \mathrm{bp}$ product of the mother $I I \cdot 2$ and patient III.5. Data indicate the loss of exons 45 to 55 from the dystrophin $m R N A$ transcript. are produced from an mRNA deletion of exons 45 to 54 and 44 to 54 respectively.

A summary of all detectable RNA deletions compared to the DNA deletion is given in fig 7.

\section{Discussion}

The detection of altered PCR amplified dystrophin mRNA fragments owing to deletions, insertions, or point mutations has created new possibilities for carrier determination in DMD/BMD families. The DMD family presented in this paper underlines a problem in the application of this method for carrier determination because of alternative splicing events.

In the DMD patient of this family, we found an out frame DNA deletion of exons 45 to 54 . The same deletion was also detectable at the RNA level. Alternative splicing events on the $5^{\prime}$ or $3^{\prime}$ end of the deletion, extending it by an exon, create two in frame RNA deletions of exons 45 to 55 and 44 to 54 respectively.

For the grandmother (I.2), aunt (II.4), and one cousin (III-8) of the patient, dystrophin mRNA analysis shows no altered fragment resulting from deletion. For the mother (II-2) and sister (III.2) of the patient we detected an mRNA deletion of exons 45 to 55 which extends the DNA deletion by one exon at the $3^{\prime}$ end and was also present in the patient himself. Therefore both females should be treated as carriers. In addition to the disease causing deletion, the mother of the patient has two further in frame mRNA deletions of exons 45 to 47 and 45 to 48 explicable by alternative splicing in the normal allele because she also has the undeleted fragment.

The carrier status of the second cousin (III.6) of the patient is still ambiguous. Here we detected an mRNA deletion of exon 44 in addition to the normal fragments. This mRNA deletion could be explained either by alternative splicing or by a new mutation. Although PCR product analyses of exon 44 at the DNA level (data not shown) indicate no strong gene dosage effect the latter possibility cannot be completely excluded.

This family illustrates a problem for the application of dystrophin mRNA analysis for $\mathrm{DMD} / \mathrm{BMD}$ carrier diagnosis owing to various alternative splicing events and the possibility of new mutations.

We wish to thank Dr K E Davies for helpful discussion. The work was supported by Deutsche Forschungsgemeinschaft.

1 Bakker E, Bonten EJ, De Lange LF, et al. DNA probe analysis for carrier detection and prenatal diagnosis of Duchenne muscular dystrophy: a standard diagnostic procedure. 7 Med Genet 1986;23:573-80.

2 den Dunnen JT, Bakker E, Klein Breteler EG, Pearson PL van Ommen GJB. Direct detection of more than $50 \%$ of van Ommenne muscular dystrophy mutations by field inversion gels. Nature 1987;329:640-2.

3 Laing NG, Siddique T, Bartlett R, et al. Duchenne muscular dystrophy: detection of deletion carriers by spectrolar dystrophy: detection of deletion carriers by sp-8.

photometric densitometry. Clin Genet 1989;35:393-8.
Speer A, Kräft U, Hanke R, et al. Deletion analysis of Speer A, Kräft U, Hanke R, et al. Deletion analysis of DMD/BMD families from the German Democratic Republic and selected regions of $\mathrm{Cz}$ ary. F Med Genet 1990;27:679-82. A highly informative CACA repeat polymorphism 


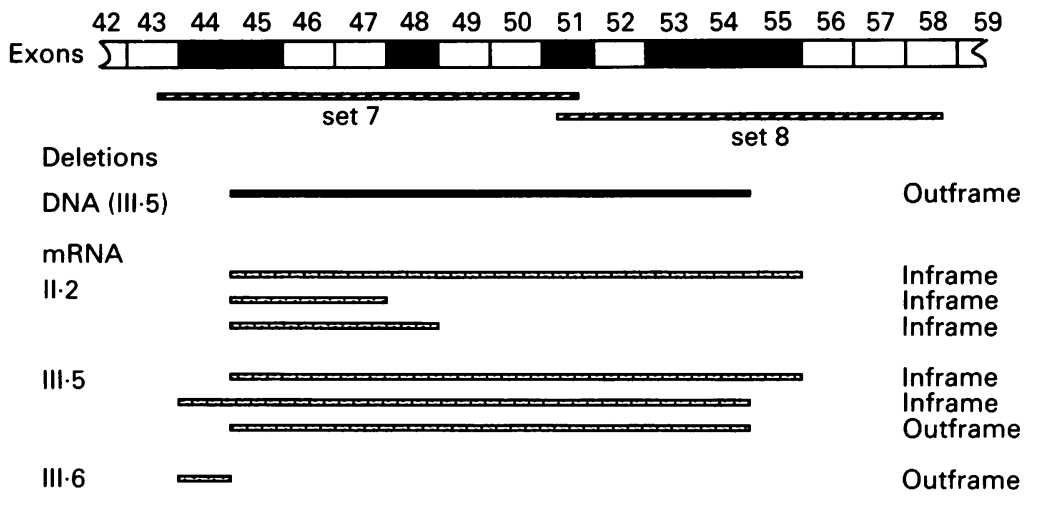

Figure 7 The diagram summarises all detectable DNA and mRNA deletions in the region of exons 43 to 58. Shaded boxes represent exons which were amplified from genomic DNA. Regions of dystrophin transcript which were amplified by RT-PCR are designated beneath the exon diagram (set 7 and set 8 ). Black bar represents the extent of DNA deletion identified with cDNA probes cf56a,b and PCR of genomic DNA. Shaded bars designate the extent of all detectable $m R N A$ deletions in the family members tested in our study. Effects on the translational reading frame are indicated to the right of the diagram. upstream of the human dystrophin gene (DMD). Nucleic Acids Res 1991;19:3159.

6 Love DR, England SB, Speer A, et al. Sequences of junction fragments in the deletion-prone region of the dystrophin gene. Genomics 1991;10:57-67.

7 Chelly J, Kaplan JC, Maire P, Gantron S, Kahn A. Transcription of the dystrophin gene in human muscle and non-muscle tissues. Nature 1988;333:858-60.

8 Chelly J, Concardet JP, Kaplan JC, Kahn A. Illegitimate transcription: transcription of any gene in any cell type. Proc Natl Acad Sci USA 1989;86:2617-21.

9 Roberts RG, Bentley DR, Barby TFM, Manners E, Bobrow M. Direct diagnosis of carriers of Duchenne and Becker muscular dystrophy by amplification of lymphoBecker muscular dystrophy by amplific
cyte RNA. Lancet 1990;336:1523-6.

10 Roberts RG, Barby TFM, Manners E, Bobrow M, Bentley DR. Direct detection of dystrophin gene rearrangements by analysis of dystrophin mRNA in peripheral blood ymphocytes. Am f Hum Genet 1991;49:298-310.

11 Chelly J, Gilgenkrantz H, Lambert M, et al. Effect of the dystrophin gene deletions on mRNA levels and processing in Duchenne and Becker muscular dystrophies. Cell 1990;63:1239-48.

12 Chelly J, Gilgenkrantz H, Hugnot JP, et al. Illegitimate transcription-application to the analysis of truncated transcripts of the dystrophin gene in non-muscle cultured cells from Duchenne and Becker patients. $\mathcal{I}$ Clin Invest 1991;88:1161-6.

13 Ehrenpreis J, Hillers M, Junker B, Pfordt M, Schwinger E, Vosberg MP. Analysis of a dystrophin gene deletion by Vosberg MP. Analysis of a dystrophin gene deletion by amplification of mRNA isolated from DMD myotubes cultured in vitro. Genomics 1991;10:551-7.

14 Schlösser M, Slomski R, Wagner M, Reiss J. Characterization of pathological dystrophin transcripts from the lymphocytes of a muscular dystrophy carrier. Mol Biol Med 1990;7:519-23.

15 Chomczynski P, Sacchi N. Single step method of RNA isolation by acid guanidinium thiocyanate-phenol chloroform extraction. Anal Biochem 1987;162:156-9. 